fewer than we might expect, for the civilian is allowed to show manifest fear or to run away. That some kinds of psychoneurotic people should retire to the West Country - as many did during 1914-18 - is best for everybody. He regretted the use of a phrase now rather popular, namely, 'fright neurosis'. Fear is of biological significance, and to be afraid, even greatly afraid, is, in some conditions, a natural reaction. Pathological fear is in a very different category, the reaction being usually quite inadequate to the situation.

Nor is it right to class all psychoneurotics in one group; some of them can be diagnosed as likely to break down in peace or war, and some will not ; others will withstand the most difficult conditions. Some who had managed to adjust themselves to the last War and to the years since have broken down now, suppressed memories of the last War being touched up. To confuse such cases with 'fright neurosis' is disastrous.

How civilians will behave in air raids is difficult to predict. It is possible that some with a high degree of claustrophobia will prefer to be bombed rather than have the feeling of being in an enclosed space; within a shelter some may faint, and others may adjust to the circumstances although feeling considerable discomfort. With regard to the question of what can be done with cases of uncontrolled behaviour or of those who faint in an air-raid shelter, Dr. Culpin said that the fainting neurotic might be left to himself, while harsh treatment might be needed for others.
Two schools exist in the medical profession with regard to the treatment of the neurotic who has broken down: one is the school which would diagnose and treat by psychological means, and the other he called the 'kick in the pants' school. Fortunately for the world, the latter is found chiefly among the elderly, who are despised by the younger and more adequately trained doctors.

Mr. Alec Rodger, discussing the selection and grading of personnel, said that a great stimulus to this was provided by the Americans in the War of 1914-18. In order to sort out people fit for different kinds of training, nearly two million men were given intelligence tests. The experiment proved so successful that other countries, including Germany and the U.S.S.R., have adopted similar intelligence testing procedures. Mechanical aptitude tests have also been widely employed. Both intelligence and mechanical aptitude tests and other psychological techniques are used to a limited extent in our own fighting Services.

The value of tests in the grading of personnel needs special emphasis. Many are accustomed to think of them only as instruments in the selection of men and overlook the fact that they can be used effectively in the grading process, the aim of which is to arrange that individuals of similar abilities are instructed together. Mr. Rodger added that, since intelligence tests had been used by many school and other authorities over a period of years, much data of value to the Services could probably be made available immediately.

\title{
CENTRAL REGISTER OF SPECIALISTS
}

\section{(SeCtion For Scientific Research)}

WN the issue of Nature of April 8, 1939, p. 575, there was an account of the establishment by the Royal Society and the Ministry of Labour jointly of the Central Register of Specialists (Section for Scientific Research), with the main aim of providing a list of scientific workers whose professional services might be useful in time of war. It will be remembered that each scientific worker was asked to fill in a card giving an account of his qualifications and some details of his career. From the point of view of the Royal Society the register also had a secondary purpose, for, if there were not to be a war, then it was felt that this was a good opportunity to obtain a census of the scientific knowledge of the country which would be of general value. With the outbreak of war the main purpose of the register was called into play, even before its compilation was complete, and it will be of interest to give a short account of some of its consequent workings. This article only deals with the register of men of science, and does not touch on the similar work of the Ministry of Labour in other branches of learning or technology.

In the spring of 1939, cards were sent out to men and women whose names had been furnished by certain learned societies. Up to the end of July a little short of eight thousand had been sent out and some five thousand replies received. Since July, several hundred more have been sent out to people who had been missed in the earlier lists, and the total number of cards returned is now more than six thousand. This list is largely composed of names from universities, from industries and from the research associations. Men already in the Government service have also been permitted to send in their cards, so that they are 
included in the census; though of course their services are already at the disposal of the Government, so that for them the more immediate function of the register does not arise. The committee of men of science which is helping to work the register is subdivided into panels composed of experts in each subject, and during the summer the panels met to sort out and classify their cards. There are, of course, great differences in the characters of the various subjects, and there was great uncertainty in the natures of the expected demands, and so no uniformity was attempted in the practice of the different panels. For example, the engineers and physicists subdivided their list into quite small groups, whereas in mathematics it was inappropriate to do this because, apart from the leading experts in each branch whose names would be well known, general mathematical skill is easily transferable from one subject to another.

On the outbreak of the War, the register immediately began to function. A certain number of leading men of science had already been earmarked for service directly, so that it was for junior posts that the register was specially useful. Recourse to the register is now the normal procedure for filling all scientific posts in the Government service when these are of the standard of the register. The way the register operates is usually somewhat as follows. The Government department requiring staff presents a written: demand to the register for the staff that is needed in order to fill a certain number of posts, stating the nature of work, the qualifications required and the salary offered. A preliminary selection from the cards in the register is made by the staff of the Ministry of Labour with the advice and assistance of the expert panels, and often of technical representatives of the departments. The selection is then submitted to the appropriate panel so that the selections can be considered, and if necessary discussed with a technical representative of the ordering department. In this way the quality of the man needed can be more accurately assessed. When a final selection has been made, the men selected are circularized and are asked whether they are willing to be considered for the post offered provided that their employers are willing to release them. Thus the department concerned receives from the register what is practically a short list of suitable candidates who are known to be willing to take the post offered. The department then itself arranges for interviews and makes the appointments, and the Ministry of Labour takes no further part in the proceedings, except to record appointments.

It may be appropriate here to refer to a matter which has received some attention though it is not directly connected with the register. In many laboratories a number of men are doing co-operative research, and it was felt that the operation of the register, which deals with individuals, might seriously endanger such work by taking away some members, possibly even though they might be only minor members, of such teams. The question of safeguarding scientific teams was entrusted to the Department of Scientific and Industrial Research. The matter proved by no means easy, because a team is a very indefinite thing. For example, in one university a laboratory might with equal justice be regarded as either one or several teams, while in another, with quite as good a scientific record, the work of the members would be so independent that it would hamper their usefulness to call them a team at all. In the end it was settled that (with one or two special exceptions) there were to be no teams in universities, since if the operation of the register was in danger of spoiling important team work it would be easy for the university or the head of a department to make (as 'employer') representations to that effect. On the other hand, there was danger that the production of industry might be seriously hampered by draining away the members of its research teams, and so the research laboratories of a number of firms have been registered as teams. Their members cannot be called on through the machinery of the register without consultation with the Department of Scientific and Industrial Research.

The register has now been working for more than four months and it is possible to review some of its results. It appears that it has well justified the effort put into its preparation. For the most important appointments it was of course scarcely necessary, as the likely candidates for such appointments would be familiar to any adviser, but for other appointments it has been most useful, so that wherever a need has arisen in the Services, names could be put forward to meet it. In some of the subjects the demand has exceeded the supply, but there are a good many where the opposite is the ease. As might be expected, the biological subjects are not in great demand for matters connected with the Services, and few new outlets for them are apparent in agriculture or industry ; it looks unlikely that, for example, there will ever be calls for more than a limited number of zoologists or botanists as such. On the other hand, certain categories have become practically exhausted of scientific men. The question of training people for rare categories is being examined, and persons with 'secondary' qualifications in them are used when possible.

Consideration has been given to the point that it is now possible to say that a good many of those on the register who are reserved under the Schedule 
of Reserved Occupations will probably never be called on to use their professional knowledge for war purposes in a civil capacity, and the possibility has been examined of notifying them that they are released from their reservation. It was felt that it would be very invidious to take the initiative in this, but machinery has been set going to arrange for the possibility of release. It will be open to any scientific man reserved under the Schedule to apply for release, and his case will be considered by the appropriate panel. In arriving at its decision, the panel will give consideration to any representation by the applicant's employer (university, firm, etc.), and to the possibility that the applicant's professional services might be needed later, even though the demand is not yet apparent. In view of the differences of demand in the various scientific subjects, each panel is adopting its own policy, but broadly speaking the general poliey will be that release will be granted to anyone who is unemployed or likely to become so, while for others the grant will only be made after much more careful consideration of each application.

\section{O B I T UAR IES}

Sir Francis Goodenough, C.B.E.

GIR FRANCIS GOODENOUGH died on January 11, after a long period of ill-health, at the age of sixty-seven. It is possible to surmise that had he come under the influence of a science master at an impressionable age, as has happened to many of us, he would have made a career in some branch of science which would have gained a great leader. As it was he performed what is perhaps the more difficult feat, namely, the introduction of some measure of planning and science into commerce.

$\mathrm{He}$ lived to see the subject of management adorned by the adjective 'scientific' and to participate in international congresses under the double heading. He was one of the first and greatest salesmen in the gas industry, where he emphasized the importance of supplying a service as well as a commodity. Equally valuable were his services in the cause of education applied to gas engineers and gas salesmen. Here he insisted that the scheme, elaborated in conjunction with the City and Guilds of London Institute, should be one of education as distinct from examina. tion only. It is known that the early difficulties in connexion with this were almost overwhelming, and that but for his patience it would have been difficult to overcome them.

Sir Francis was a pioneer of co-operative advertising and a leader of many other co-operative movements both within and without the gas industry. A man of rare vision and large ideas, fuculties usually involving impatience, he was characterized by an easy and genial manner and the quality of complete sincerity. In addition to his successful career with the Gas Light and Coke Company, which he saw rise from something very much smaller to its present outstanding position, he was always visualizing developments ahead of the time.

Sir Francis was one of those who will probably appear greater in retrospect than he does at the time of his activities, when personalities and policies hold the stage. Science and commerce lie perhaps on opposite sides of the river of daily endeavour, but many bridges are being built across the river, over which traffic struggles in either direction. One such bridge builder was Goodenough; the edifice he has erected, built on sound foundations, will stand the stresses of stream and wind and the increasing load of progress for many years to come. E. F. ARMStrong.

\section{Miss E. K. Pearce}

Miss Ethel Katherine Pearce, whose death occurred on January 8, at Morden, Dorset, at the age of eighty-three, was an entomologist who devoted her energy and enthusiasm almost entirely to Diptera. A daughter of a vicar of Morden, she had around her one of the finest entomological hunting grounds even in a county as favoured as Dorset. The first series of her work, "Typical Flies", a photographic atlas in which the author sought to popularize and extend the study of an order of insects much neglected in those days, was published in 1915. A preface giving practical guidance for collecting and preservation is followed by a sketch of Brauer's classification of the Diptera, and his sixty families are named, the Aphaniptera (fleas) being included. The forty-five pages of reproductions from photographs, considering the great difficulty of such work, are admirable, the flies figured being all recognizable and characteristic. In some cases preliminary stages are shown. The photographs of typical Dorset localities are a very pleasing and helpful feature. They not only give information as to the habitat of the fly, but also tempt the Nature lover to explore such delightful environment.

The flies taken as types of the various families were chosen with the help of the late. Prof. Theobald, F. C. Adams, and other capable authorities, with great care. A second series appeared with 125 photographs in 1921, and a third series with 162 photographs in 1928. In all, fifty-five out of the sixty families of flies enumerated by Brauer are represented in the three series by a type fly. The brief biological notes given under the figures add much to the interest of the book. The author was helped, too, in her work by her brother, Mr. N. D. R. Pearce. 